\title{
LA PARTICIPACIÓN DEL ARTE Y LA LITERATURA EN LA CONSTRUCCIÓN DISCURSIVA DE UNA HISTORIA DE LA EDUCACIÓN
}

\author{
The participation of art and literature in the discursive \\ construction of a history of education
}

\section{Anna Gómez i Mundó}

Fecha de recepción: 09/06/2016 • Fecha de aceptación: 02/10/2016

Resumen. El artículo centra su atención en observar y valorar los elementos que el arte y la literatura ofrecen para llevar a cabo la interminable tarea de comprensión de la historia de la educación. Lo hace considerando tanto los procesos de creación artística como sus expresiones, no solo como fuentes documentales con las que investigar, sino también como experiencias, objetos y discursos que nos abren la posibilidad de reconocer y pensar algunos elementos epistemológicos y metodológicos para nuestro quehacer investigador.

El contenido va desarrollándose a modo de discusión al tiempo que expone aquellos aspectos relevantes para la articulación de un posible discurso de la historia de la educación. Ayudándose de la relación mantenida con las diferentes artes y la literatura, la autora describe e indaga aquello que va encontrando a lo largo del proceso de observación, análisis y reflexión que ha realizado hasta llegar al punto de conclusión - siempre inacabada - con el que cierra el artículo. Así es como la lectura del texto conduce a la admisión de considerar que todas las metodologías de investigación - tanto las que hayan contado con la asistencia de las artes y la literatura como las que no- pueden llegar a devenir una experiencia que contiene, crea y proyecta una estética.

Palabras clave: Dimensión estética; Elementos metodológicos; Concepciones epistemológicas; Arte e historia de la educación

\begin{abstract}
This article focuses its attention on observing and evaluating the different elements which the arts and literature can contribute to the boundless

\footnotetext{
" Departament de Pedagogia. Facultat d'Educació, Traducció i Ciències Humanes. Universitat de Vic-Universitat Central de Catalunya. C. Sagrada Família, 7, 08500 Vic. Barcelona. Espanya. anna. gomez@uvic.cat
}

Cómo citar este artículo: Gómez Mundó, Anna. «La participación del arte y la literatura en la construcción discursiva de una historia de la educación», Historia y Memoria de la Educación, 5 (2017): 239-281. 
endeavour of understanding the history of education. This is done by considering the processes of artistic creation together with their expressions not only as documentary sources used for investigation but also as experiences, objects and discourses which open the possibility of recognising and considering certain epistemological and methodological elements of our research.

The content is presented in the form of a discussion, exposing those aspects that are relevant to the articulation of a possible discourse of the history of education. Resorting to the relationship existing between the different arts and literature, the author examines and describes her findings, reached through the process of observation, analysis and reflection, working towards the conclusion - always unfinished-which closes the article. In this way a reading of the text leads to the consideration that all research methods -whether aided by the arts and literature or not - may be seen as experiences that contain, create and project an aesthetic.

Keywords: Aesthetic approach; Methodological elements; Epistemological conceptions; Art and history of education.

La historia empezó antes que nosotros y, aunque a menudo se ha presentado como algo debidamente delimitado y situado cumpliendo coordenadas de tiempo y de espacio, continúa suscitando interrogantes acerca del contenido de su relato.

Aun así, la atención de este texto no solo se centra en los elementos que dan lugar al contenido del discurso histórico, sino más bien intenta dar cuenta del camino recorrido para hallar dichos elementos. Se trataría, entonces, de presentar las conexiones que los recorridos metodológicos mantienen con el enunciado resultante de ellos. Así, se podría decir que la idea que sirve de base para las siguientes reflexiones es que para comprender y articular los discursos de la historia de la educación no solo debemos atender a las prácticas, hechos, ideologías y actores que la conforman, sino también a los procesos, perspectivas, disposiciones sensibles e intelectuales que han permitido llegar a la construcción y divulgación de dichos discursos.

Habida cuenta de que el interés del presente monográfico gira alrededor de la relación que se establece, o puede establecerse, entre las prácticas artísticas y la educación, detengámonos a pensar de qué manera el estudio de la historia de la educación puede encontrar en las expresiones artísticas no solo fuentes documentales fecundas en información, sino también un faro epistemológico que ayude a la adopción de una vía metodológica sensible ante lo que la literatura y el arte le ofrecen. 


\section{APERTURA Y SENSIBILIDAD}

Alguien me dijo «es imposible construir una memoria si no dejas que te digan». Lo pronunció con ese tono que lleva consigo la obviedad, parecido al que se usa para comunicar las evidencias, los a priori de una cuestión. Y pensé de inmediato que en esas palabras retumbaba algo que contenía verdad. Si la historia empezó antes que nosotros, los recuerdos con los que las memorias van configurándose viven en los cuerpos de quienes la vivieron, en cuerpos que padecieron, gozaron e interpretaron lo acaecido. Otros los contaron con un orden más o menos coherente, más o menos plausible, más o menos acorde con el curso aceptado de las cosas. Y por canales escritos, orales o plásticos, en contextos informales o académicos, llegaron a nuestros cuerpos. Nos llegó al cuerpo entero.

Ser conscientes de la participación integral del cuerpo en el proceso de estar en y ante la historia debería traducirse, entonces, en una disposición epistemológica que permita y acoja la posibilidad de que entren en juego no solo el intelecto desencarnado, sino también todo aquello que, aunque incomprensible por el momento, se asome por una rendija en el mismo acto de conocer. Con la voluntad de situarse de forma clara ante sus detractores, Paulo Freire, el pedagogo brasileño, afirmó:

Me gustaría manifestar de inmediato mi recusación a cierto tipo de crítica cientificista que insinúa que falta rigor en el modo como discuto los problemas y en el lenguaje demasiado afectivo que uso. La pasión con que conozco, hablo o escribo no disminuye el compromiso con que denuncio o anuncio. Soy una totalidad y no un ser dicotómico. No tengo una parte esquemática, meticulosa, racionalista y otra desarticulada, imprecisa, que quiere bien de manera simplista el mundo. Conozco con mi cuerpo entero, sentimiento, pasión. También razón. ${ }^{1}$

La supuesta objetividad con la que se decía que debía trabajar aquel que pretendiera hacer ciencia quedaba en entredicho con el argumento de la dimensión política que contiene toda decisión humana.

Parecería fácil, por consiguiente, que se empezara a admitir que cada quien lleva consigo sus filias y sus fobias. Parecería honesto enunciar

\footnotetext{
${ }^{1}$ Paulo Freire, A la sombra de este árbol (Barcelona: El Roure, 1997), 18.
} 
desde qué concepción cada cual se aproxima a los temas que le ocupan su tiempo e interés. Incluso parecería innecesario volver a traer a colación las anteriores cuestiones a tenor de la dimensión espiritual que, junto a la física y la psicológica, se reconoce como elemento constitutivo de la condición humana. Pero la obviedad que nos empujaría a dejar de lado este viejo debate se encuentra todavía velada. Aun admitiendo las complejas conexiones entre percepción, emoción, razón e imaginación presentes en la experiencia de un mismo individuo, a la hora de pensar los procesos de construcción, transmisión y aprendizaje de saberes se sigue colocando el acento más enfático en la razón lógica.

Este trimestre, la clase de párvulos trabajará Miró. Cuando una niña de cuatro años ve por primera vez un cuadro del pintor lo mira y lo admira: señala con felicidad la presencia de su color preferido en él, ve serpientes donde yo veo trazos, ve pelotas esparcidas por una tela que le gusta; «ies una fiesta!», exclama. Una manera bien distinta de cómo su madre ha vuelto a mirar aquella obra después de pasar por el instituto. La madre quiere acompañar el proceso de aprendizaje de su hija en la escuela, así que va a la biblioteca a documentarse, compra tarjetas postales de reproducciones de su obra, bucea por internet para que se pueda familiarizar con las obras del pintor y sus nombres. Con todo esto, la maestra seguirá con su propuesta de educación plástica. Sea como sea lo que suceda a partir de este momento, la cuestión que llama la atención es la diferente disposición con la que ambas, niña y mujer, establecen su relación con el cuadro. Una percibe y desde ahí dice, conecta, significa, expresa. La otra mira, organiza, racionaliza. También percibe y siente, sin duda, pero a estas alturas parece que la formación académica recibida acerca de la obra artística la haya inclinado a establecer una relación más mediada con la obra.

Como la de tantas otras personas, mi relación con las creaciones artísticas ha sido mediada por las instituciones educativas desde muy temprana edad. De forma explícita — como podría ser la tematización de una creación artística dentro de los contenidos curriculares- o implícita —como lo serían aquellos mensajes que circulan por el conocido currículum oculto-, la mayoría de los adultos hemos ido articulando una relación con el arte que ha ido desplazando lo sensorial y creativo para dejar en el centro aquello más racional del arte; la experiencia enteramente corporal ha ido perdiendo parte de sus elementos para que- 
darse con aquello más reconocible como conocimiento. El carácter de la formación recibida ha sido acorde con la concepción epistemológica dominante, la que entiende como conocimiento solo aquello que responde a la razón aristotélica y que formula los juicios bajo el cobijo de una determinada autoridad.

Una de las huellas de dicha concepción epistemológica la podemos rastrear en las distintas y cuantiosas ocasiones donde la educación de la sensibilidad se ha confundido con la transmisión de la sistematización de cánones estéticos despojados de emoción, de reflexión y de participación en la dotación de significado por parte de quien participa de la experiencia de conocer. $\mathrm{O}$, al contrario, también la confusión se ha plasmado al concentrarse únicamente en la transmisión de la emoción —a veces incluso solo con el estímulo de la emoción- sin la participación del pensamiento. Con ambas confusiones se ha tendido al establecimiento de un reduccionismo que podemos identificar como lo que ha llevado a la educación de la sensibilidad a transitar por un pasaje que la ha casi obligado a desaparecer bajo el término de educación emocional. La concepción sinonímica entre ambos términos es una amenaza, pues, tanto para la comprensión y concreción práctica del desarrollo de una dimensión fundamental del ser humano y de su participación en el proceso educativo, como para la tarea de llevar a cabo la comprensión de su historia.

A la vez, el proceso de tematización curricular que han sufrido muchas de las artes ha contribuido de manera importante al establecimiento del distinto valor de una y de otra y, dentro de cada una, de los registros valiosos y menores. Qué merece estar en un museo y qué no, qué es buena literatura y qué no, qué es pregunta de examen y qué simple entretenimiento banal.

Cuando los caminos están tan marcados, cuando los movimientos artísticos se encuentran tan señalados o tan formada se encuentra la estética y la decodificación de los símbolos del contexto cultural en la que una ha vivido su particular «proceso de civilización», resulta complicado abrirse a otros significados, a sentir otras sensaciones que las ya asociadas al color rojo, a la serpiente o a la rosa.

Aquí está pasando algo interesante, a la par que frecuente en nuestros tiempos. Puede que uno de los motivos por los que se llega a esta simpli- 
ficación —diría que empobrecimiento- del proceso de construcción del saber, e incluso de la misma obra artística, lo podemos hallar recorriendo la misma historia del pensamiento de nuestra tradición. Ciertamente, una de las constantes ha sido la presencia de una robusta lógica de pensamiento dual, que además a menudo ha sido enseñada y aprendida con la particularidad de establecerse a partir de dicotomías excluyentes entre sí. La razón lógica aristotélica impregnó, casi enquistándose en la experiencia de la concepción del mundo, también del saber. Y con la estrechez de pensar a partir de polos opuestos y sólidamente definidos e inquebrantables como el «todo es cierto» o «todo es falso», «todo está en orden» o "todo es caos», «todo es intelecto» o "todo es emoción», hemos ido socializándonos en una cultura del conocimiento a la que le ha sido difícil incorporar los matices, las incertidumbres y las complejidades presentes en las realidades que eran objeto de su interés. Y ello no solamente tiene implicaciones en la forma de aprenderlo, sino también en la de construirlo y divulgarlo, dando lugar al asentamiento de premisas para su validación tales como la objetividad.

Y si existen términos alejados ontológicamente entre sí, dos de ellos bien podrían ser los de arte y objetividad. Mientras uno remite a la vinculación activa con, el otro lo hace a una distancia pasiva con. Entonces, cuando de lo que se trata es de comprender las historias ayudándonos de las obras artísticas y la literatura, la distancia pasiva de la tradición epistemológica no parece ser la vía a emprender más adecuada. Si añadimos, además, el juego de tiempos que las investigaciones históricas manejan, la participación de la memoria y el recuerdo de quién investiga, o lo que está expresado en la obra artística, son elementos indispensables en el proceso. Como escribía Zweig, es todo el cuerpo, y con todas sus dimensiones, lo que participa en la narración de una historia:

Pero nuestra generación ha aprendido a conciencia a no llorar las cosas perdidas y, además, quién sabe si la falta de documentación y de detalles no acabará redundando en beneficio de este libro. Porque yo no considero a nuestra memoria como algo que retiene una cosa por mero azar y pierde otra por casualidad, sino como una fuerza que ordena a sabiendas y excluye con juicio. ${ }^{2}$

\footnotetext{
${ }^{2}$ Stefan Zweig, El mundo de ayer (Barcelona: Acantilado, 2015), 16.
} 
La objetividad cientificista como medida de valor de un relato histórico olvida, entonces, la influencia y participación de la imaginación, del trabajo simbólico, y con el simbólico tanto de aquellos que han generado las fuentes documentales con las que se trabaja como de quienes recurren a ellas para comprender mejor aquella realidad. De la dimensión epistemológica que aquí se apunta emana —que no configura-algo más de base, así es, el estar en el mundo, como lo muestra de forma evidente, por ejemplo, la dimensión política e histórica de todo individuo.

Tal reflexión conduce a reconocer la necesidad de descolocar las coordenadas dicotómicas tradicionales y desplazarlas hacia un lugar epistemológico distinto que permita acompañarlas de constelaciones con los matices necesarios para que el trabajo de dilucidar las realidades sea más riguroso.

Cada mañana que llega nos informa de las novedades que suceden en el mundo. Pero somos pobres sin embargo en historias que tengan interés. ¿A qué se debe esto? A que ya no llegan a nosotros acontecimientos que no estén entremezclados con explicaciones. Dicho en otras palabras: casi nada de cuanto nos sucede beneficia a la narración; casi todo es informativo. La mitad del arte de la narración consiste en liberar alguna historia de explicaciones al reproducirla. ${ }^{3}$

Si ahora no se trata tanto de explicar como de comprender algo, ${ }^{4}$ la apertura a lo extraño y a lo que a la vez nos toca debería ser una primera disposición de nuestra actitud ante este oficio ocupado en la educación y en la narración de su historia. Ciertamente debe tocarnos, pues sin el punto de vinculación no puede empezar el camino de interrogación. Y ese tocar puede ser producido por los elementos comunes que compartimos con lo que encontramos en las fuentes históricas, mas también puede darse al ser contrariados por ellas, por la perplejidad que sentimos, por la provocación y el reto que nos plantea lo discordante, lo equívoco, lo misterioso.

\footnotetext{
${ }^{3}$ Walter Benjamin, Imágenes que piensan (Madrid: Abada Editores, 2014), 191.

${ }^{4}$ Albert Esteruelas y Xavier Laudo, «Del arte a la pedagogía póvera: una alteración pedagógica de lo efímero", en Actas del XVIII Coloquio de Historia de la Educación: Arte, literatura y educación, eds. Núria Padrós, Eulàlia Collelldemont y Joan Soler (Vic: UVic- UCC, 2015), 325-333.
} 
Una segunda disposición para acoger lo que la sensibilidad nos haga llegar tiene que ver con algo implícito a la apertura; eso es, al movimiento de salir de sí. Dicha apertura la promueve el estar en marcha, en movimiento, siempre en un equilibrio desequilibrado por el acontecer de la experiencia que lleva el encontrarse lo nuevo. También aquello nuevo que es el mirar lo cotidiano y que, de tan visto, ignoramos.

Quizás podríamos cambiar de perspectiva si tomásemos de la mano la imaginación y la entendiéramos como una vía más de apertura hacia aquello posible e incluso deseado; una vía nada desdeñable si reconocemos la fecundidad de saberes que nos han sido dados gracias a su participación. Las palabras de Hellen Keller - mujer que por su sordoceguera obligatoriamente tuvo que vivir incorporando la sensibilidad y la apertura a la razón- me parecen significativas para concluir las primeras reflexiones del texto:

La mayor parte del conocimiento del mundo es una construcción imaginaria. La historia no es más que una modalidad de la imaginación, una forma de mostrarnos civilizaciones que ya no están sobre la faz de la tierra. Algunos de los descubrimientos más significativos de la ciencia moderna deben su origen a la imaginación de hombres que carecían de los conocimientos y los instrumentos de precisión necesarios para demostrar sus creencias. ${ }^{5}$

\section{EL ARTE COMO PALANCA: INCERTIDUMBRES Y PROPAGANDA EN LA CREACIÓN ARTÍSTICA}

El arte no contiene en sí mismo un primer propósito de conciliación, sino de proposición de algo — cuando proyecta-, de provocación — cuando cuestiona-y de negación — cuando destruye- De las tres maneras de presentarse, aquellas que interesan por su aportación a la comunidad humana son las dos primeras. En la medida en que lanzan propuestas - posibles o imaginarias- de nuevas formas de comunicación, de narración, de relación, de concepción, etc., abren posibilidades para continuar con el trabajo simbólico que la humanidad ha debido llevar a cabo a lo largo

\footnotetext{
${ }^{5}$ Helen Keller, El mundo en el que vivo (Girona: Atalanta, 2012), 68.
} 
de su historia. En cambio, la tercera forma de presentación del arte adviene teniendo como única finalidad el anuncio del fin, de la muerte, de la no salida al interrogante planteado. Este llega igualmente a tocarnos, mas en esta ocasión lo hace para llevarnos a una desazón de tal magnitud que bloquea el trabajo simbólico, sustrae una de las dimensiones constitutivas de lo humano. En él no hay trampolín hacia una actividad creadora sino, a lo sumo, hacia una resignación fatalista. Las expresiones artísticas que voy a contemplar, pues, son las que se orientan por la apertura, bien porque proyectan —lanzando e insinuando propuestas-, bien porque interrogando críticamente las propuestas actuales provocan la necesidad de actuar y transformar el statu quo del presente.

En ambos casos, el arte invita a la imaginación de algo más, distinto, crítico o fantástico, diferente a lo ya dado, a lo ya pensado, a lo asentado.

No obstante, siendo más precisos, deberíamos convenir que, si bien en la provocación y proposición encontramos la invitación de los elementos anteriores, el arte y sus expresiones también pueden utilizarse - como se ha hecho ampliamente a lo largo de la historia- como medio propagandístico de ideas más o menos cerradas o de modelos sociales más o menos rígidos. En estos casos, se intenta controlar la potencia polisémica de la creación artística para garantizar que el mensaje que quiere comunicarse llegue sin ningún resquicio de dudas a los destinatarios, cerrándoles el paso a participar en la construcción de significado para que incorporen nítidamente la consigna transmitida gracias al soporte artístico. Sin movernos de nuestro contexto, encontramos multitud de creaciones que han sido cooptadas para representar un significado unívoco. Otra forma de utilizar el arte como propaganda de ideologías ha sido recurrir a su lenguaje para comunicar e instruir al público. En este caso, nos referimos a la producción pictórica, musical, fílmica, etc., expresamente orientada al fin de la difusión ideológica.

Pero cuando el arte abre a algo distinto que escapa del control del autor y sumerge al sujeto que lo recibe en un movimiento hacia un lugar distinto al que se encuentra, el arte deviene claramente palanca de creación de algo, también de saber.

Entonces, quien goza de los momentos de estar en relación con lo artístico desde la apertura y con la sensibilidad al servicio del aconteci- 
miento deja de ser estrictamente la pedagoga que estudia las prácticas educativas en tal o cual contexto, deja de ser únicamente la profesora de historia del arte, deja de ser estrictamente el catedrático de estética en ejercicio. Todos ellos dejan de ser lo que dicen ser para abrirse a lo que les toca, a lo que les hace tambalear y sentir de otra manera. El ser que mantiene esta suerte de relación con las creaciones artísticas se deja decir incluso aquello que no encaja, incluso aquello que le molesta y lo desmiente. Se deja decir, y así se encamina por otros caminos al que le ha llegado marcado, sale del méthodo conocido - y peligrosamente confirmado como válido-, y se adentra a explorar lo que le abre la propuesta artística. Se encuentra con la incertidumbre que habita en todo limbo de significado, con el baile de luces y sombras de lo conocido y lo desconocido:

Hay arte y literatura donde no se afirma rotundamente lo que es y donde tampoco se asiste a la simple desposesión de la nada. Lo artístico y lo literario existen en tanto lo que es aparece con la nada y donde la nada se muestra con lo que puede ser. Hacer arte o escribir es algo que sucede cuando se evitan declaraciones absolutas y también cuando el creador no se abandona de modo total al vértigo de la nada. Se llega a ser artista y escritor aprendiendo a tratar con lo que es como si pudiera no ser y con lo que no es como si pudiera llegar a ser. ${ }^{6}$

Según lo veo yo, la relación con la literatura y las demás expresiones artísticas también conlleva una disposición similar a la del artista y escritor creador de ellas, pues en la relación que mantenemos con ellas durante nuestro tiempo de ocio o durante nuestra tarea de poner más focos de luz en la comprensión de la realidad —si al arte recurrimos como fuente documental- estamos aprendiendo (porque así lo estamos viviendo) a tratar con lo que es como si pudiera no ser y con lo que no es como si pudiera llegar a ser. En esos momentos necesitamos acompañar la desorientación que sentimos con la confianza en nuestra capacidad de significar, de indagar, de nombrar y de convivir con el misterio. Dicho de otra manera, necesitamos saber que la incomprensión que hallamos en los primeros momentos, incomprensión que

\footnotetext{
${ }^{6}$ Néstor García Canclini, El mundo entero como lugar extraño (Barcelona: Gedisa, 2015), 76-77.
} 
puede prolongarse a lo largo de mucho tiempo, no es signo de error o de fracaso, sino la certeza de que nos encontramos realmente ante algo artístico. Puede ser, por tanto, que el momento de creación artística mantenga algo en común con el momento en el que se encuentra quien quiere comprender.

Paradójicamente $-\mathrm{O}$ no-, mientras nos atrevimos sin demasiados reparos al resto de las creaciones artísticas y literarias no lo hacemos de igual manera con el arte plástico contemporáneo. Así, una de las respuestas más frecuentes ante el arte contemporáneo es la de cerrarse en lugar de abrirse, la de dar por perdida la relación establecida mucho antes de lo que lo haríamos cuando tuviésemos la seguridad de que allí detrás hay una respuesta correcta posible de ser descubierta. La reacción más extendida ante el arte contemporáneo es la de revestirse con un armazón protector, descartando cualquier tipo de diálogo, dimitiendo así de la posibilidad de ser más y de saber más que antes de cruzarnos con la creación. Ahí no existe apertura, ni posibilidad de sentir. ¿Será una reacción de comodidad?, ¿de cobardía?, ¿de desidia?, $¿$ de acartonamiento intelectual? Me he detenido a interrogarme acerca de este tipo de relación establecida con lo contemporáneo porque cabe la posibilidad de que las escenas de armaduras protectoras no sean exclusivas de nuestra época, y así como hoy asociamos la contemplación de una obra de Modigliani al placer estético podría ser que para sus coetáneos no significase precisamente lo mismo.

Será, a lo mejor, que la literatura y el arte exigen que nos despojemos de la comodidad que da conocer las zonas por las que nos movemos en lo cotidiano para que a continuación podamos salir a la intemperie, un espacio bastante dado a las sorpresas e imprevistos. Un lugar cuyo orden difiere del que ya sabemos descodificar, un lugar de conformación cultural libre aún de convencionalismos, un espacio posiblemente inteligible siempre y cuando nos relacionemos activa y plenamente con él, aceptando estar en un movimiento constante desnudo de ambages y despojado de barandillas en cada paso que demos. En efecto, al adentrarnos en el mundo artístico, los pasajes empujan a pensar de otra manera dibujando paisajes posibles, deseables, soñados, ideados, concebidos con las herramientas de la imaginación y del pensamiento. Los pasajes no entienden de cronogramas ni secuencias, no se orientan por programaciones de trabajo. Jaume Plensa 
lo dijo en una intervención televisiva con otras palabras más breves y a la par más concisas: el arte llega cuando tiene que llegar. La llegada de aquello que impulsa el inicio del proceso de creación artística, lo que enciende y hace crecer la necesidad de crear, no puede anticiparse por el mero recibimiento de un encargo. Su desarrollo es desigual entre los autores, siendo diverso el método de trabajo, el material, el concepto..., pero si uno quiere salir de la casilla de producir piezas y entrar a la intemperie de crear arte no puede anticipar cómo se desarrollará el proceso creativo ni dónde lo llevará. Tampoco lo sabe quién lo disfruta.

Del mismo modo entiendo la educación, tal como una obra de arte que es creada cuando quien educa se sitúa en el acto educativo habitándolo para que aparezca la siempre incierta experiencia, cuando ante los estudiantes se abre a la tarea de proponer y provocar el aprendizaje y con ellos comparte su también acto creativo de trabajar con el simbólico para significar sus aprendizajes: «la classe és una obra d'art, la qual cosa obliga el professor a no perdre de vista els alumnes, els veritables destinataris d'aquesta obra d'art efímera però que tal vegada perdura en el record». ${ }^{7}$

El carácter efímero del acto educativo puede haber contribuido a no considerar la dimensión artística y de creación viva que contiene. El valor de la materialidad ha desbancado el valor de lo inasible, de lo no catalogable, de lo no que se deja prender de forma total y absoluta, nada más y nada menos que aquello que nos plantea la experiencia educativa. Una experiencia que cada vez es más difícil de acoger e impulsar en nuestros tiempos, apretada como está por la urgencia de dar constancia material del trabajo educativo. La visibilidad de plantillas, boletines de calificaciones, de materiales didácticos visibles, aunque se presenten sobre soportes digitales, etc., centran mucho más la atención que aquello que puede suceder a quienes dan vida a la educación con el estar y la acción de sus cuerpos. Paralelamente a esta característica, por lo que se refiere a aquello que ha sido de interés para el saber de la historia de las prácticas educativas y los recursos con los que se ha ayudado el área de rastrear la historia para comprender qué pasaba, cómo se concebía, qué se pensaba..., estos han sido más próximos a las 7 Conrad Vilanou, «Quan fer classe esdevé art: la pedagogía com estètica», Temps d'Educació, 49
(2015): 315. 
materialidades que a lo más etéreo e intangible. Obviamente las fuentes eran más asequibles, los marcos más dibujados, la escritura fijaba negro sobre blanco las bases ideológicas y programáticas del movimiento pedagógico..., y todo ello contribuía a facilitar la investigación porque sin duda nos daba y nos sigue dando buena parte de la seguridad necesaria para persistir y sostenernos en el reto de comprender realidades distantes en el tiempo o en el espacio.

No obstante, aquello que sostiene la propuesta programática o la adecuación de los materiales didácticos no son sino los actos que los traducen en realidad viva y concreta. El libro de texto está allí y se puede analizar su contenido, pero el uso y la significación que los participantes le dan devienen elementos singulares, muchas veces efímeros e inmateriales. Aquello que nos abre a lo etéreo es la recepción y su agencia.

Nada más lejos de mi intención afirmar que los documentos con los que se trabaja en la investigación no tengan validez, ni que de ellos no podamos aprender nada más acerca las cuestiones de interés para la historia. Más bien querría saber introducir la cuestión acerca de lo inasible, movedizo e incierto que conlleva la investigación con y de lo artístico, también de lo educativo.

Veamos un paso más en el desarrollo de las consideraciones acerca de la dimensión artística de la experiencia educativa y sus consecuencias en la investigación de su historia.

\section{LA ESTÉTICA EN LAS METODOLOGÍAS DE INVESTIGACIÓN}

El hecho estético está latiendo por todas partes. En las últimas décadas, por ejemplo, el número de testimonios que dan cuenta de lo estético que se encuentra en el acto de caminar se ha incrementado notablemente. Parece que se está recuperando la antigua condición nómada incorporando la práctica de andar en los procesos creativos de índole artística y de performatividad humana. La modalidad del vagabundeo, de carácter más bien errático, se contrapone a la de la marcha planificada de la excursión, aunque se admite que ambas comparten el acto del caminar como experiencia estética. Sean itinerarios por paisajes urbanos, sean recorridos por paisajes nítidamente naturales, aquello que ofrecen al in- 
dividuo son experiencias estéticas, experiencias nacidas de la relación de apertura a la percepción de lo que se descubre a su alrededor. ${ }^{8}$

La conexión entre el caminar y el pensar también ha sido un aspecto ampliamente relatado y reflexionado por variados y dispares protagonistas. Incluso ha sido sistematizado por algún movimiento, siendo el situacionista uno de los más representativos con su aporte de las derivas como modo de conocer y establecer relación con el mundo. ${ }^{9}$ Caminar, pensar, leer y nombrar no son acciones ajenas a nuestro mundo, ni siquiera a nuestro oficio investigador. De ello sentí que me hablaban las palabras que siguen: «El método es pasear por las palabras y, de vez en cuando, sentarse con ellas ante el diccionario de la experiencia». ${ }^{10}$

En el caminar, ${ }^{11}$ el contacto, la exploración y la percepción del espacio físico crea situaciones que lo transforman en un hecho estético, transformación que de la misma manera que al andar puede suceder al pasear por los textos literarios.

Lo literario ofrece al lector un amplio abanico de posibilidades de ser de otra manera, de pensar desde otros puntos de vista, de significar de modos divergentes al propio. La experiencia estética de la lectura abre

\footnotetext{
${ }^{8}$ En la actualidad, existen múltiples y diversas experiencias que dan cuenta del interés por recuperar y actualizar las posibilidades que abren las prácticas de deriva. A modo de ejemplo, la aparición del documento "No todos los que vagan están perdidos», una publicación ideada, diseñada y maquetada por Andrea Galaxina en junio de 2015, después de la recopilación de las experiencias de deriva a las que invitó a realizar y documentar. El proyecto puede consultarse en http://bombasparadesayunar. com (consultado el 31-5-2016). Tal interés ha llevado también a la ideación de propuestas que quieren abrirse a la posibilidad de vivir dichas experiencias de formación en distintos contextos con voluntad explícita de devenir educativos, como lo muestra - a modo de los muchos ejemplos que podemos citar- el proyecto Caminants. Del proyecto precedente, al que llamaron Assajant Caminants, escriben en su página http://www.derivamussol.net/assajant-caminants/: «Les passes del caminar i la seva poètica ens regalen infinits camins més enllà de l'acció física i ens acompanyen a racons on poder jugar amb l'invisible i construir conjuntament l'imaginable». Esta iniciativa surge de Deriva Mussol, una propuesta de creación artística ideada por Eva Marichalar y Jordi Lafon.

${ }^{9}$ Un trabajo muy interesante acerca de cómo la deriva encuentra espacios en contextos educativos y de investigación de nuestra actualidad es el que podemos leer en Mar Estrela y Eva Marichalar, «Aprendre amb la deriva: Una mirada compartida», Temps d'Educació, 48 (2015): 111-127. En él escriben: «La «deriva» és per nosaltres una actitud davant els processos d'aprenentatge, creació i recerca. La deriva no és el pitjor que ens pot passar en educació, sinó ben al contrari: plantejar-nos un futur incert ens connecta de forma immediata al present dels nostres sentits i ens du a observar, compartir i descobrir» (Estrela y Marichalar, «Aprendre amb la deriva», 112).

${ }^{10}$ Esteruelas y Laudo, «Del arte a la pedagogía póvera: una alteración pedagógica de lo efímero», 328.

${ }^{11}$ En este punto me es imprescindible reconocer el excelente trabajo que Jordi García Farrero realizó acerca de esta cuestión en su tesis doctoral «Caminar i pedagogia en la modernitat: una aproximació fenomenológica i hermenéutica» orientado por la dirección del Dr. Héctor A. Salinas y del Dr. Conrad Vilanou (Universitat de Barcelona, 2013). Parte del trabajo puede leerse en Jordi García, Caminar. Experiencias y prácticas formativas (Barcelona: UOC, 2014).
} 
las compuertas a otros modos de comprender la realidad descrita en la obra, lo que sugiere que la diversidad de modos de ver, habitar, significar y representar la realidad indica la naturaleza calidoscópica de la realidad, empujándonos a pasar de hablar de realidad a hablar de realidades. En este sentido, tanto la diversidad de interpretaciones que abren las creaciones artísticas como la gran heterogeneidad de sus lenguajes y manifestaciones - musicales, literarias, plásticas, corporales, cinematográficas...-, así como la pluralidad de sus creadoras y creadores, pueden llegar a ser percibidos y considerados como problemas obstaculizadores del propósito de la investigación, cuando lo que se busca es una razón explicativa monolítica y sin fisuras del hecho investigado.

Sin duda alguna, la complejidad obliga a desplazarse de manera importante desde la seguridad hacia otra zona poblada de más incertidumbre de las que a menudo sentimos ser capaces de asumir. Atender a la experiencia a la que nos lleva la obra artística obliga, pues, a desplazar definitivamente la razón lógica aristotélica y abrazar otra que permita una aproximación más verdadera a la comprensión de dicha realidad.

Una consideración, la anterior, relativamente sencilla de decir y argumentar, pero claramente ardua y complicada de seguir, pues nuestro proceso de enculturación ha sido predominantemente dirigido por un orden de pensamiento lineal, monocausal y dicotómico. Sin embargo, la esperanza está en que la conciencia de la naturaleza de nuestro centro de interés puede animar la voluntad de incorporar cada vez más asiduamente la perspectiva y los procesos que abracen tal naturaleza en nuestras metodologías de investigación.

El advenimiento del hecho estético aparece, como hemos expuesto hasta ahora, al caminar con los pies, con los oídos, con la piel y con los ojos, pues la sensibilidad abre los canales del sentir y del pensar, de la percepción y la reflexión. La sensibilidad abre la actividad de la razón poética, de la construcción de un saber amplio y sensible a lo humano.

Las posibilidades que abre la literatura en el aprendizaje y cultivo de la sensibilidad son, en ese sentido, especialmente significativas y relevantes en la cuestión que nos ocupa. Tal vez, la literatura es la fuente artística que más ha contribuido en los ámbitos académicos a desarrollar su función de investigar y divulgar el conocimiento. Lo digo por la larga 
tradición que se ha apoyado en ella a través de la práctica de la citación. En las citas literarias no pocas veces hemos hallado el empuje a dar un salto de comprensión, a alzar la mirada hacia otros rincones del que estábamos atendiendo, a valorar la existencia de otras formas de acercarnos a la comprensión de los hechos y los sentimientos, a imaginar otras salidas posibles cuando estamos embarrancados en nudos de pensamiento, a descubrir palabras más rigurosas y precisas para decir lo que hasta el momento nos era indecible. Pero como todo arte, la cita no aparece sin la participación de la sensibilidad que sabe percibir la potencia, la belleza, la ruptura, la luz..., que alberga el fragmento que se escoge. ${ }^{12}$

Ahora bien, el largo recorrido que la cita tiene de participación en las prácticas del pensamiento académico muestra que no siempre han servido para salirse de los raíles preestablecidos. Encontramos también utilizaciones instrumentales de citas en las que, al entrelazarse con textos academicistas, muere su potencia estética. Y con esta muerte estética aquello artístico se desplaza hacia la función de propaganda anteriormente expuesta. Emilio Lledó lo reflexiona en las siguientes palabras, mostrando además la consecuencia que tiene el investigar tan solo con una parte del cuerpo, esto es, la de pensar que también los textos son muertos, producciones sin alma:

En esto consistiría un equívoco academicismo que partiese del principio de que lo que el texto especula es tan liso y escurridizo como la metáfora que le sirve de sustento. El texto habla de problemas que tienen sentido y son dialogables, porque interesan a la mente que lucha por entenderlos. Aunque dormido en la aparente tranquilidad de lo escrito, quien habla en texto es una voz humana que ha hecho el recorrido del saber y del conocimiento por vericuetos semejantes a los que el texto expresa. [...] El academicismo olvida este carácter vivo del texto. Encerrado en un esquema que sustenta esa estructura del prejuicio a que, anteriormente, se hizo mención, desconoce, sin embargo, su posible fecundidad, que nos une con el pasado, y que, en cierto sentido, nos prepara a la tarea de comprender. ${ }^{13}$

\footnotetext{
${ }^{12}$ Desarrollo más ampliamente esta cuestión en Anna Gómez, «La cita: punt de partida, acompanyant i fita en l'elaboració de textos», Papers d'educació, 5 (2007): s/p, consultado el 15 de enero de 2016, URL: http://mon.uvic.cat/papers-deducacio/files/2012/08/05FonsDocumentalLaCita.pdf

${ }^{13}$ Emilio Lledó, El silencio de la escritura (Madrid: Espasa, 2011), 66-67.
} 
Lo que nos recuerda que en esta otra forma de escribir lo pensado, en esta epistemología olvidadiza de vida, también hay estética, contiene su estética; es una propuesta estética. De ahí que, bien sea caminando con la sensibilidad, bien se haga con un cuerpo disociado, me atreva a afirmar que la metodología de investigación es una estética.

Las metodologías de investigación participan y colaboran en la creación o reproducción cultural. Por la posición epistemológica con la que orientan sus decisiones y sus prácticas, las metodologías pueden actuar trabajando con lo simbólico y, como resultado de ello, pueden lanzar nuevos significados para persistir en el intento de comprensión de la realidad. En todo caso, no sería tarea nueva para el investigador que tome esa opción, ya que, como nos recuerda Duch, el trabajo con lo simbólico es una actividad que llena de contenido la condición humana:

Existir equivale a crear símbolos y a moverse (interpretar) en ámbitos de pensamiento, sentimientos y acciones simbólicamente configurados, porque resulta muy evidente que el hombre, estructuralmente, es capax symbolorum. La actividad simbólica no es algo sobreañadido de manera artificiosa a la humanidad del hombre, sino que le pertenece sustancialmente y ya se encuentran señales de su enraizamiento estructural desde sus mismos orígenes prehumanos. ${ }^{14}$

Si el ser humano es capax symbolorum, dicha dimensión no se circunscribe al marco de unas capacidades específicas, sino que está en todas aquellas que se mueven en el ámbito del pensamiento y la creación; o sea, en áreas propias de la esfera cultural de la humanidad. Por ello podemos afirmar que la propuesta de significación que contiene el arte lo sitúa claramente en la dimensión cultural del hombre y de su comunidad, y en ella su deseo de seguir buscando el más, la transcendencia, la mejora y ensanche del ser y de su estar en relación con el mundo. Las obras artísticas son concreciones de este anhelo, y con su existencia van configurando cultura y pueden, con su difusión en el mundo común, pasar el testimonio del trabajo con lo simbólico en todos aquellos contextos donde se dan experiencias de aprendizaje cultural.

\footnotetext{
${ }^{14}$ Lluís Duch, Antropología de la vida cotidiana. Simbolismo y Salud (Madrid: Trotta, 2002), 47.
} 
Hasta el momento, hemos planteado el carácter provocativo en tanto que interrogador y/o propositivo del arte y la literatura. Esta característica definitoria lleva en ella el deseo que da la fuerza al individuo para intentar un proceso de creación, esto es, el deseo de acercarse a una verdad, la que sea. Incluso se identifica la presencia de alguna verdad como indicador de que aquello que se está creando es arte, es literatura. El escritor Herman Koch lo decía recientemente en una entrevista: «A veces me doy cuenta que hay algo de provocador en aquello que escribo, pero como veo que hay algo de verdad en ello, lo dejo». ${ }^{15}$

Con la búsqueda y participación de algo verdadero, aunque sea una verdad inacabada y provisional, repleta de dudas y consecuentemente humilde, incorporo un elemento más de los que participan en una de las estéticas posibles y en la que yo me reconozco. A partir de dicho reconocimiento, diría que el gusto por lo bello de lo estético y lo bueno para los seres nos llevan a estar en busca de algo que contenga algo de verdad, búsqueda que debería movernos a quienes investigamos porque si bien se mira: «Eso es lo que hace el pensamiento: ir más allá de lo que inmediatamente somos, pero no para encontrar cualquier cosa, sino algo que sea, de algún modo, verdad». ${ }^{16}$ En cambio, cuando la producción artística está orientada a la propaganda no provoca ni insinúa verdad, sino que la pretende propagar unívocamente, sin dar espacio a la percepción del receptor, obedeciendo así a la función que se le ha encargado; difunde $s u$ verdad, una verdad.

La belleza en la investigación de la historia de la educación sería el trabajo de búsqueda de un punto de verdad mediante la necesaria valentía que se necesita ante la inevitable incertidumbre de llevar a cabo una investigación, el reconocimiento de quienes nos acompañan en dicha tarea, ${ }^{17}$ la apertura sin censura de la sensibilidad de cada quien y la

\footnotetext{
${ }^{15}$ Entrevista a Herman Koch, emitida el 23 de marzo de 2016 en el programa Página 2. Accesible en http://www.rtve.es/television/20160322/estimado-senor-herman-koch-habla-sobre-educacion-relacion-profesores-alumnos-mundo-libros/1323643.shtml.

${ }^{16}$ Marina Garcés, Filosofía inacabada (Barcelona: Galaxia Gutenberg, 2015), 11.

${ }^{17}$ Mis circunstancias no me permiten agradecer la colaboración de becarios - porque no tengo-, pero sí quiero y debo reconocer y agradecer el apoyo, la compañía y el estímulo intelectual que incesantemente he recibido de la Dra. Eulàlia Collelldemont durante la realización de este artículo.
} 
honestidad que merece dar cuenta a la comunidad de todos los pliegues, los faros y los escollos con los que nos hemos encontrado en el proceso.

El último requisito, el de la honestidad de contar el proceso, no es algo superfluo ni debería ser entendido como la parte anecdótica, y por tanto prescindible de una investigación. Al menos yo no lo entiendo así. En más de una ocasión, sentimos satisfacción al encontrar el hallazgo que perseguíamos sin preguntarnos cómo hemos llegado a ello, quién o qué nos ha dado la mano -o nos lo ha puesto difícil-. El gozo no debería cegarnos, pues si nos acomodamos en él caemos en el riesgo de ocultar algo de gran importancia epistemológica y metodológica, esto es, el lugar que dicha observación, dato, documento, idea, etc., ocupa en la amplia cartografía de la historia del patrimonio material e inmaterial de la educación.

Y quien quiera acercarse a lo que es su pasado sepultado tiene que comportarse como un hombre que excava. Y, sobre todo, no ha de tener reparo en volver una y otra vez al mismo asunto, en irlo revolviendo y esparciendo tal como se revuelve y se esparce la tierra. Los "contenidos» no son sino esas capas que sólo después de una investigación cuidadosa entregan todo aquello por lo que vale la pena excavar: imágenes que, separadas de su anterior contexto, son joyas en los sobrios aposentos de nuestro conocimiento posterior, como quebrados torsos en la galería del coleccionista. Sin duda vale muchísimo la pena ir siguiendo un plan al excavar. Pero igualmente es imprescindible dar la palada a tientas hacia el oscuro reino de la Tierra, de modo que se pierde lo mejor aquel que sólo hace el inventario fiel de los hallazgos y no puede indicar en el suelo actual los lugares en donde se guarda lo antiguo. Por ello los recuerdos más veraces no tienen por qué ser informativos, sino que nos tienen que indicar el lugar en el cual los adquirió el investigador. Por tanto, stricto sensu, de manera épica y rapsódica, el recuerdo real debe suministrar al mismo tiempo una imagen de ese que recuerda, como un buen informe arqueológico no indica tan sólo aquellas capas de las que proceden los objetos hallados, sino, sobre todo, aquellas capas que antes fue preciso atravesar. ${ }^{18}$

\footnotetext{
${ }^{18}$ Walter Benjamin, Imágenes que piensan (Madrid: Abada Editores, 2014), 140-141.
} 
Mirar y contar, recordar y documentar, escuchar y deshacer el camino transitado para dar cuenta del recorrido realizado durante el proceso, con sus detalles, desvíos, sensaciones y rupturas o conexiones encontradas y establecidas. Un modo que me atrevería a decir que no permite la linealidad monótona del tránsito por un largo y extenso altiplano, sino más bien exige dirigirse hacia un trayecto sinuoso y errante que, ya al inicio, se presenta impredecible por el misterio de la diversidad de experiencias que abre. ${ }^{19}$

Apostar por este tipo de caminos y vivir las trayectorias que abren es un modo de estar en el mundo, un modo de hacer mundo, de mirarlo y comprenderlo. Las actitudes, las concepciones, las prácticas, las decisiones o las finalidades del para qué investigar son algunos de los muchos elementos que hacen del investigar una experiencia configuradora y divulgadora de cultura. En efecto, debe reconocerse la fuerte dimensión cultural que se encuentra en el hacer investigador, y dicho reconocimiento emana no solo de su vertiente divulgadora, sino también de los elementos (de tiempos, de ensayo, de búsqueda de una verdad, de su carácter provocador y propositivo...,) que comparte con las prácticas de creación.

De todo ello, y a modo de síntesis, termino subrayando lo que se ha pretendido plantear en ese artículo: las metodologías de investigación, con su trabajo de lo simbólico y con lo simbólico, configuran cultura. Desde ahí es cuando, al fin, llegamos a la idea de que las metodologías de investigación, con o sin la asistencia de las artes y la literatura, pueden llegar a devenir una experiencia que contiene, crea y proyecta una estética.

\footnotetext{
${ }^{19}$ Sin embargo, debo admitir que esta propuesta no tiene demasiadas posibilidades de ser aceptada fácilmente ni de hacerse un lugar cómodo en nuestros tiempos. El orden cartesiano goza de un fuerte estado de salud, y la necesidad e imperativo de poner orden está por todas partes, siendo un tipo de orden difícilmente amigo de las derivas, el vagabundeo, el extravío y la libertad de dar sentido desde sí al mundo. Una muestra de ello, y no menor a mi parecer, es el dato que nos ha dado el último Sant Jordi: el primero de las listas de ventas de los libros de ficción en lengua castellana ha sido La magia del orden. Herramientas para ordenar tu casa... iy tu vida!, de Marie Kondo. En catalán, ha ocupado el nada despreciable tercer puesto.
} 


\section{Nota sobre la autora:}

Anna Gómez i Mundó (Centelles, 1973) es doctora en Pedagogía por la Universitat de Vic (2011). Actualmente es la coordinadora de los estudios de Educación Social en la Facultat d’Educació, Traducció i Ciències Humanes de la Universitat de Vic. Desarrolla su tarea docente en los grados de Educación Social, Magisterio en Educación Primaria y en Educación Infantil. Su formación y primera experiencia docente la realizó en la Facultat de Pedagogia de la Universitat de Barcelona. Sus ámbitos de investigación contemplan cuatro ejes de interés: la práctica y la relación educativa, la historia cultural, la investigación narrativa y la memoria educativa. Pertenece al GREUV y ha participado en proyectos de investigación competitiva en el área de patrimonio educativo. Tiene publicados diferentes artículos acerca la educación con personas adultas, la investigación narrativa y la historia de la educación. 